\title{
Short-Term, Faculty-Led Study Abroad and Global Citizenship Identification: Insights from a Global Engagement Program
}

\author{
Lucy W. Mule \\ Shannon Audley \\ Kathryn Aloisio \\ Smith College
}

\begin{abstract}
:
Short-term, faculty-led study abroad programs are increasingly featured in higher education internationalization efforts. As noted in the literature, such programs can aid in the development of varied student outcomes, including developing global citizenship. This paper presents an examination of the Global Engagement Seminar (GES) program, a short-term, faculty-led program at a private women's liberal arts college that has expressed a firm commitment to internationalization. A quasi-experimental design was employed to examine whether participation in the GES program influenced participants' antecedents, identification, and pro-social values of global citizenship (Reysen \& Katzarska-Miller 2013a), and how the relationships compare with those of a matched comparison sample. The results of the survey indicated that GES completion moderated some but not all of the paths in the global citizenship model. Completing a GES was associated with non-significant relations among the moderated paths, a finding that emphasizes the need for a nuanced discussion of the complex relationship between short-term study abroad and global citizenship. Implications for faculty-led global engagement programs that aim to promote global citizenship among undergraduates in liberal arts contexts are discussed.
\end{abstract}

\section{Introduction}

Short-term, faculty-led study abroad programs are increasingly featured in higher education internationalization efforts. Keese and O'Brien (2011) defined faculty-led programs as "a creditgranting college-level study abroad program where faculty accompany students from their universities as teachers and trip leaders" (p. 5). These programs and regular study abroad overlap in their goals to provide students with carefully designed learning experiences across national boundaries that promote a wide range of student outcomes, including the development of global citizenship (Aktas, Pitts, Richards, \& Silova, 2016; Di Gregorio, 2015; Mullens \& Cuper, 2012). However, despite their increasing prominence in higher education, the research on student outcomes and program effectiveness of short-term, faculty-led programs is still in nascent stages (Gullekson, Tucker, Coombs, \& Wright, 2011; Walters, Charles, \& Bingham, 2016). The purpose of the present study is to examine the effect of one short-term, faculty-led study abroad program, known as the Global Engagement Seminar (GES), on students' understanding of themselves as global citizens. 
GES is a short-term, faculty-led program at a private women's liberal arts college that has expressed a firm commitment to internationalization. The program, according to the college website, was offered in the 2011-2016 academic years as a series of intensive, credit-bearing summer seminars taught by a team of faculty offered at a location away from the campus. That it was designed to enhance the global engagement of participants is evidenced by the title of the program as well as its administration, which was located in the Global Studies Center of a college with a declared commitment to global engagement in its various manifestations, including study abroad. Each GES included mandatory meetings throughout the spring semester to prepare students academically and culturally for their experience away from campus; an intensive seminar taught abroad in May and/or June by a pair of faculty from two different academic disciplines; and a required international community-based service learning experience following the academic seminar. The faculty chose the academic focus of their GES and worked with staff in the Center on logistics related to study abroad and international service learning. It was expected, as is typical in short-term, faculty-led programs, that the faculty would target issues or topics that could be explored in their international context. Altogether, six countries, 14 faculty and a wide range of topics/issuesincluding gender politics, sustainability, archeology, arts, peace, culture, and cities-were represented. One seminar was offered three times and two were offered twice during the six-year period. The first author co-designed and twice co-taught one of the GESs.

As a case study, the GES program allows for an exploration of whether participation in a shortterm, faculty-led program influences participants' global citizenship, a term that, as explained in the next section, is defined in this paper as "awareness, caring, and embracing cultural diversity while promoting social justice and sustainability, coupled with a sense of responsibility to act." (Reysen, Pierce, Spencer, \& Katzarska-Miller, 2013, p. 5). The findings of such a study provide insight into the potential and limitations of similar programs in single-handedly promoting global citizenship among students. Using the results of the global citizen survey (Reysen \& Katzarska-Miller, 2013a) administered to students involved in the GES program and a matched sample of students who did not participate in the GES program, the authors examined the extent to which students (1) selfidentified as global citizens; (2) expressed pro-social values commonly associated with this selfidentification; and (3) differed, if at all, based on participation in the GES program.

The next section is a review of the literature on short-term, faculty-led programs, highlighting the benefits and challenges of such programs. A brief discussion follows on the ways that such programs may relate to the goal of developing global citizenship among student participants. Also presented is an argument for empirical exploration of the relationship between global citizenship and short-term, faculty-led programs amid the growing acknowledgement of the connection between the two.

\section{Literature Review}

\section{Short-Term, Faculty-Led Programs}

Short-term, faculty-led study abroad programs are a large portion of students' study-abroad experiences (Di Gregorio, 2015). However, these programs, which usually are summer programs or eight weeks or less, are not uniform. They often vary depending on (a) how often they are offered, (b) where participants are housed, and (c) who initiates, controls, and administers the program (Keese \& O'Brien, 2011). They also vary on whether they incorporate an international experiential 
component (e.g., project-based study), service learning, or community-based research (Barkin, 2016; Graham \& Crawford, 2012; Gullekson et al., 2011; Lewis \& Niesenbaum, 2005; Sachau, Brasher, \& Fee, 2010). A review of the literature on short-term, faculty-led programs indicates ways in which these programs may influence student development, as well as their perceived limitations.

Such programs often include students who have had no prior international travel and/or who lack the funds or time for extensive study abroad experiences (Lee \& Green, 2016; Mullens \& Cuper, 2012); facilitate personal growth, transformative learning, and professional development (Di Gregorio, 2015; Mullens \& Cuper, 2012; Walters et al., 2016); approximate outcomes accrued from longer study abroad programs (Lewis \& Niesenbaum, 2005); lead to subsequent international travel and engagement (Coryell, Stewart, Wubbena, Vavverse-Poenie, \& Spencer, 2016); and facilitate the development of outcomes associated with global citizenship, especially when they are integrated with relevant academic content (Perry, Stoner, Stoner, Wadsworth, Page, \& Tarrant, 2013; Tarrant, Rubin, \& Stoner, 2014). Short-term programs have also attracted a good deal of criticism. They have been criticized for their potential to be "academically light," provide few opportunities for deep interaction with host countries, and promote "academic" tourism (Di Gregorio, 2015); promote a neoliberal view of global citizenship (Aktas et al., 2016; Di Gregorio, 2015); perpetuate systems of power and privilege (Aktas et al., 2016; Fisher \& Grettenberger, 2015); and promote fewer outcomes compared to semester and year-long study abroad experiences (Dwyer, 2004; Kehl \& Morris, 2008).

Despite these weaknesses, short-term, faculty-led study abroad programs continue to gain support in higher education. Their proliferation has led to increased conversation within and across fields (such as global education, study abroad, international service learning, and academic areas such as business, geography, and social work) about elements that are more successful at fostering desired student outcomes. Regarding student learning outcomes related to global citizenship, a majority of studies on short-term study abroad report increases in outcomes such as global awareness (Chieffo \& Griffiths, 2004; Kurt, Olitsky, \& Geis, 2013; Wang, Peyvandi, \& Coffey, 2014), intercultural, personal and professional competencies (Drnach, Ruby, Kluender, Palomba, \& Ursick et al., 2016; Zamastil-Vondrova, 2005), pro-environmental behavioral intentions (Landon, Tarrant, Rubin, \& Stoner, 2017; Tarrant et al., 2014), global-mindedness (Kehl \& Morris, 2008), and some forms of civic engagement (Mulvaney, 2017).

However, some researchers have cautioned that, as with study abroad in general, the benefits of short-term study abroad vis-à-vis on-campus study need to be thoroughly researched (Chieffo \& Griffins, 2004; McKeown, 2009; Tarrant et al., 2014). Others have found that the impacts of study abroad can be mixed, especially when a comparison group or strategies for checking selection bias are included (Gullekson et al., 2011; Mulvaney, 2017; Salisbury, An, \& Pascarella, 2013). For example, Mulvaney (2017) compared long-term behaviors of students who studied abroad (59\% of participants had participated in short-term programs) with those who did not, in four areas. In the area of civic engagement and awareness, Mulvaney reported that positive responses on study abroad surpass the non-study abroad responses in only four of the nine indicators surveyed. Salisbury et al. (2013) controlled for selection bias in a large, multisite longitudinal study of the effect of study abroad on intercultural competence among undergraduates and found that the development of intercultural competence was influenced by personal characteristics, such as ethnicity, gender, and 
campus experiences, as well as study abroad experiences. It appears that the positive impacts of short-term study abroad can become muted when control groups are utilized.

In the present study, the authors employed a quasi-experimental design to examine whether participation in the GES program influenced participants' antecedents, identification, and pro-social values of global citizenship, and how the relationships compare with those of a matched comparison sample. The term "global engagement program" is hereafter used to refer to programs, such as the GES program, which are short-term, faculty-led, and involve both academic study and service learning abroad. As mentioned above, such programs have become more common in higher education, and they often identify "global citizenship development" as one of their goals and desired student outcomes (Coryell et al., 2016; Kiely, 2004; Mullens \& Cuper, 2012; Tarrant et al., 2014).

\section{Global Citizenship and Faculty-led Global Engagement Programs}

In the broader field of study abroad, a consensus on the definition of global citizenship is elusive, despite its prominence as an expected student outcome for many programs. Aktas and colleagues (2016) pointed to the complexity of the term when they posited that its definitions reflect broader conversations and debates about the meanings and conceptualizations of global processes, and reflect three dominant approaches: neoliberal; radical / conflict; and critical/ transformationalist. Programs informed by the neoliberal approach are likely to concentrate on developing competencies related to enhancing students' mobility and employability in a competitive global market. Programs informed by the radical approach are likely to emphasize an analysis of global structures and power relations, while those in the critical perspective focus on agency and social transformation. The term is also seen to be highly contextualized. Reysen, Larey, \& Katzarska-Miller (2012) noted that different disciplines tend to privilege some understandings of global citizenship over others. For example, social work may focus more on social justice, while programs in the field of education may focus on global awareness. Because of the competing understandings of the term, study abroad programs are increasingly being urged to articulate the meanings of global citizenship that frame their values and learning outcomes (Landon, et al., 2017; Tarrant et al., 2014).

With regard to researching global citizenship, several concerns exist. Reysen et al. (2012) suggested that because global citizenship has been approached from a variety of perspectives and backgrounds, often from a non-empirical approach, there is not a clear definition of global citizenship, hence its relations with outcomes variables are unclear. To make the concept viable for research, Reysen and colleagues (2013) suggested viewing global citizenship as an abstract, and psychological, social category. The social identity approach, they argued, allows the researcher to focus on participants' understanding of themselves as global citizens. Their definition of global citizenship as "awareness, caring and embracing cultural diversity while promoting social justice and sustainability, coupled with a sense of responsibility to act" emphasizes this self-understanding as well as a focus on global citizenry values often associated with the radical and critical meanings of global citizenship.

Several factors make the social identity literature especially useful to the present study on whether participation in GES program influences participants' global citizenship (antecedents, identification as global citizens, and pro-social outcomes). First, it acknowledges that global 
citizenship is a mindset that can be researched. Second, the literature suggests that there is a positive, linear relationship between a student's global citizenship identification and the prosocial values and behaviors of intergroup empathy, diversity, social justice, environmental sustainability, helping others, and feeling responsible to act to better humanity (Reysen et al., 2013). Indeed, global citizenship identification (GCI) is uniquely related to these prosocial values and behaviors, whereas the norms associated with other identities (e.g., human, American) are not (Blake, Pierce, Gibson, Reyesen, \& Katzarska-Miller, 2015; Reysen et al., 2013).

Third, the studies have found that a student's embedded environment influences global awareness, knowledge of the world and interconnectedness with it, and subsequent GCI (Reysen \& Katzarska-Miller, 2013a, 2013b; Reysen et al., 2012). For example, Reysen et al. (2012) found that a "globally-infused curriculum" increased students' global awareness, which in turn engendered in students, by the end of the semester, greater global citizenship identification and prosocial outcomes. In two related studies, Blake et al. (2015) examined whether students' perception of (a) the college environment and (b) specific college courses valuing global citizenship predicted students' global citizenship identification. The first study found that the antecedents to predicting GCI, which included the student's perception of whether the college environment valued global citizenship, predicted both students' normative environment (i.e. friends and family support global citizenship) and global awareness and subsequent prosocial outcomes (i.e., intergroup empathy, valuing diversity, social justice, environmental sustainability, intergroup helping, and felt responsibility to act). The results of the second study indicated that, in reference to specific coursework, a student's perception that the course encouraged understanding of the larger world indirectly predicted GCI and its subsequent prosocial outcomes through normative environment and global awareness. Thus, both studies concluded that student's embedded environments, at the college level and the classroom level, can indirectly influence GCI and subsequent prosocial values and behaviors.

While the above-cited literature has not necessarily examined global citizenship in the context of faculty-led global engagement programs, it has explored how students' global identification relates to their perceptions of learning contexts and experiences that infuse global content (Blake et al., 2015; Gibson \& Reysen 2013; Reysen \& Katzarska-Miller, 2013b; Reysen et al., 2012). We consider short-term, faculty-led academic study abroad that is integrated with international service learning, of which the GES program is an example, to rate highly on the global content scale, and therefore find this literature useful.

In the present study, we set out to examine whether participation in the GES program influences the antecedents, identification, and prosocial values of global citizenship, and how the relationships compare with those of a matched comparison sample. Our goal in undertaking this study is to contribute to the growing pool of research on the evaluation of short-term, faculty-led study abroad programs.

\section{Method}

Study Participants

As explained in the introduction, the GES program comprised 12 seminars over a six-year period (2011-2016). Each seminar ranged between nine and 14 students, for a total of 118 students. 
The initial sample consisted of the 118 individuals who were enrolled in the GES program and a comparison group $(n=118)$, selected by a nonparametric matched paired design (Ho, Imai, King, \& Stuart, 2007; Randolph, Falbe, Manuel, Balloun, 2014), where each of the GES program participants was matched (on ethnicity/race, major, first-generation status, graduation year, financial aid, and nationality, using the college's student database) with a student who did not participate. The design allowed the inclusion of a group that shared the same characteristics as the GES group, but did not participate in the GES program. This design also helped mitigate possible biases introduced by students self-selecting into the GES program.

\section{Measures}

The survey used in this study was adopted from Reysen and Katzarska-Miller's (2013a) model of antecedents and outcomes of global citizenship. We adapted their original 7-point Likert-type scale to a 6 -point Likert-type scale $(1=$ strongly disagree to $6=$ strongly agree $)$ in order to delete the neutral choice. The 22 items in their model are grouped in four broad categories, each of which was averaged to create a mean score (with the exception of prosocial values and behaviors where each sub-category had its own mean score), as explained below:

Normative environment. Four items (e.g., "most people who are important to me think that being a global citizen is desirable" assessed perceptions that others in the normative environment support a global citizen identity (Chronbach's $\alpha=.85)$.

Global awareness. Four items (e.g., I try to stay informed of current issues that impact international relations) assessed participants' felt global awareness (Chronbach's $\alpha=.77$ ).

Global citizenship identification (GCI). Two items (e.g., I would describe myself as a global citizen) assessed global citizen identification (Chronbach's $\alpha=.89$ ).

Prosocial values. Prosocial values were grouped into six categories: intergroup empathy, valuing diversity, social justice, environmental sustainability, intergroup helping, and responsibility to act. Two items (e.g., I am able to empathize with people from other countries) assessed intergroup empathy (Chronbach's $\alpha=.75$ ). Two items (e.g., I would like to join groups that emphasize getting to know people from different countries) assessed valuing diversity $(\alpha=.86)$. Two items (e.g., Those countries that are well off should help people in countries who are less fortunate) assessed perceptions about social justice (Chronbach's $\alpha=.82$ ). Two items (e.g., Natural resources should be used primarily to provide basic needs rather than material wealth assessed participants' perceptions about environmental sustainability (Chronbach's $\alpha=.84$ ). Two items (e.g., If I could, I would dedicate my life to helping others no matter what country they are from) assessed beliefs about intergroup helping (Chronbach's $\alpha=.92)$. Lastly, two items (e.g., Being actively involved in global issues is my responsibility) assessed responsibility to act (Chronbach's $\alpha=.78)$.

GES. One item (e.g., Did you participate in GES while in college?) assessed students' participation in the GES. Students indicated yes/no on this item and their response was verified by the college's Office of Institutional Research.

Demographic variables. Personal information related to graduation status, citizenship, academic major, ethnicity/race, first-generation status, Pell grant offered, and study abroad 
experience was obtained, with permission, from standard college records through the Office of Institutional Research.

\section{Data Collection Procedures}

Of the initial sample $(n=236)$, two GES program participants did not have an email address in their alumnae record and were subsequently removed from the sample. Of the 234 students contacted, five email addresses bounced (3 GES, 2 non-GES) and were also removed from analysis. At the close of the survey administration period there was a $38 \%$ response rate. After investigating the recorded responses, the final sample consisted of 72 students $(100 \%$ female; $33.3 \%$ White; $8.3 \%$ Non-White Hispanic; 2.8\% Asian; 5.6\% Black; 11.1\% Multi-racial; 15.3\% unknown; 24\% International) who had completed at least $50 \%$ of the survey. The demographics between students that had taken a GES course $(n=43)$ were mostly comparable to students who did not take a GES course $(n=29)$. Chi-square analyses revealed two demographic differences among the respondents; students who had completed a GES course, as compared to those who did not take a GES course, were more likely than expected by chance to have been offered a Pell grant $\left(\chi^{2}(N=72,2)=4.88, p\right.$ $=.027)$ and to be current students $\left(\chi^{2}(N=72,2)=5.10, p=.024\right)$. For complete description of demographics, see Table 1.

Table 1. Sample Demographics

\begin{tabular}{llll}
\hline Demographics & & GES & No GES \\
& Percent $(n)$ & Percent $(n)$ \\
\hline Student Status* & Graduated & $58 \%(25)$ & $31 \%(9)$ \\
& Current & $42 \%(18)$ & $69 \%(20)$ \\
Citizenship & US Citizen & $77 \%(33)$ & $76 \%(22)$ \\
& International Student & $23 \%(10)$ & $24 \%(7)$ \\
Student Ethnicity & White & $30 \%(13)$ & $35 \%(10)$ \\
& Student of Color & $56 \%(24)$ & $45 \%(13)$ \\
& Unknown & $14 \%(6)$ & $21 \%(6)$ \\
First Generation & & $26 \%(11)$ & $24 \%(7)$ \\
& First Generation & $74 \%(32)$ & $76 \%(22)$ \\
Pell Grant* & Not First Generation & $28 \%(12)$ & $7 \%(2)$ \\
& & $72 \%(31)$ & $93 \%(27)$ \\
Study Abroad & Pell Grant Offered & $44 \%(19)$ & $28 \%(8)$ \\
& Pell Grant Not Offered & $56 \%(24)$ & $72 \%(21)$ \\
Division of Major & & $21 \%(6)$ \\
& Non-GES SA Experience & $19 \%(8)$ & $38 \%(11)$ \\
& No Non-GES SA Experience & $47 \%(20)$ & $14 \%(4)$ \\
& Humanities & $9 \%(4)$ & $24 \%(7)$ \\
\hline
\end{tabular}

Note: $N=72$. Percentages have been rounded for ease of presentation. Six students did not report a major. ${ }^{*}$ Marks statistically significant differences in the demographics between GES and non-GES students

\section{Data Analysis Plan}

Data analyses were conducted in three stages. First, preliminary analyses were run to determine the distributional properties of the data and to examine possible demographic differences. Second, we replicated Reysen and Katzarska-Miller's (2013a) model of global citizenship with the unique sample to determine whether this model held true for a women's college that focused on social 
justice and global awareness as part of its mission. Following this, in stage three, we tested for GES course completion effects, the main research question, using multi-group structural equation modeling (MSEM). MSEM is used in path models when there may be a moderating relationship among the predictors that varies by subgroups, in this case, whether a student has completed a GES course (Múthen \& Múthen, 1998-2017). We were interested in which specific paths, if any, were moderated by GES course completion. To examine this, we first specified a constrained model, where the parameters for all paths were set equal to each other. Then, we unconstrained one path at a time and let the parameter for each sub-group, GES course completed and GES course not completed, run free. We compared the chi-square difference from the constrained model to the model with the unconstrained path. If the chi-square difference was significant, then the path was moderated (Marsh, Hau, \& Wen, 2004). We then used this model as the "new" constrained model and continued testing each subsequent path in a similar manner, until all direct and indirect paths were tested.

All models were run with M-plus 7.4 (Múthen \& Múthen, 1998-2017), with bias corrected bootstrapping $(n=5000)$ with maximum likelihood $(\mathrm{ML})$ as the estimation method. The current study used six fit-indices to assess model fit: (1) comparative fit index (CFI, Bentler, 1990); (2) the Tucker-Lewis Index (TLI, Tucker \& Lewis, 1973); (3) Root Mean Square Error of Approximation (RMSEA, Steiger, 1990); (4) the 90\% confidence interval of the RMSEA; (5) Standardized Root Mean Square Residual (SRMR, Berndt, 1998); and (6) the Chi-square value (Kline, 2005). Hu and Bentler (1999) suggested that adequate model fit occurs when CFI approaches .95 in combination with RMSEA less than .08 and SRMR less than .06. A non-significant chi-square value also indicates good model fit (Barret, 2007).

\section{Results}

\section{Stage I: Preliminary Analysis}

Descriptive data. Table 2 provides means and standard deviations. Except for the GES course completion dichotomous variables, most of the assessed variables were weakly to moderately positively correlated with each other, which is reflective of the literature in this field (see Table 3 for zero order correlations).

Table 2. Descriptive Data

\begin{tabular}{llll} 
& Mean $(\mathrm{SD})$ & Minimum & Maximum \\
\cline { 2 - 4 } Normative Environment & $4.63(0.87)$ & 2.25 & 6.00 \\
Global Awareness & $5.15(0.78)$ & 1.00 & 6.00 \\
Global Citizenship & $4.54(1.06)$ & 1.00 & 6.00 \\
Intergroup Empathy & $5.22(0.83)$ & 2.50 & 6.00 \\
Valuing Diversity & $5.39(0.78)$ & 2.50 & 6.00 \\
Social Justice & $5.44(0.61)$ & 3.00 & 6.00 \\
Environmental Sustainability & $5.60(0.67)$ & 3.00 & 6.00 \\
Intergroup Helping & $5.44(0.75)$ & 2.50 & 6.00 \\
Responsibility to act & $5.41(0.72)$ & 3.00 & 6.00 \\
GES Course & $0.60(0.49)$ & 0.00 & 1.00 \\
Graduation Status & $0.52(0.50)$ & 0.00 & 1.00 \\
Risk Factors & $0.47(0.50)$ & 0.00 & 1.00 \\
US Citizen & $0.77(0.43)$ & 0.00 & 1.00 \\
Study Abroad & $0.53(0.50)$ & 0.00 & 1.00 \\
\hline
\end{tabular}

Note: $n$ 's ranged from 69-72. Item means are averages of the scale. Risk factors is composed of whether or not a student was one of the following: person of color, Pell grant offered, and/or first-generation student. 
Table 3. Correlations among Normative Environment, Global Awareness, Global Citizenship, and Prosocial Behaviors

Normative Environment (NE)

Global Awareness (GA)

Global Citizenship (GC)

Intergroup Empathy (IE)

Valuing Diversity (VD)

Social Justice (SJ)

Environmental Sustainability (ES)

Intergroup Helping (IH)

Responsibility to Act (RA)

GES Course $(0=$ no; $1=$ yes $)$

Note: $n s$ ranged from $67-70 . * p<.05 ; * * p<.01 ; * * * p<.001$

\begin{tabular}{llllllllll} 
NE & GA & GC & IE & VD & SJ & ES & IH & RA & GES \\
\hline 1.00 & .17 & $.60^{* * *}$ & $.29 *$ & $.44^{* * *}$ & $.29 *$ & .14 & .09 & $.44 * * *$ & .11 \\
& 1.00 & $.27 *$ & .14 & $.25^{*}$ & .11 & .23 & .19 & .21 & -.14 \\
& & 1.00 & $.28^{*}$ & $.49^{* * *}$ & $.38^{* * *}$ & $.29 * *$ & $.29 *$ & $.50^{* * *}$ & .06 \\
& & & 1.00 & .22 & .07 & .13 & .23 & .09 & .00 \\
& & & & 1.00 & $.50^{* * *}$ & $.29 *$ & $.48^{* * *}$ & $.57 * * *$ & .07 \\
& & & & & 1.00 & $.50^{* * *}$ & $.35^{* *}$ & $.37 * *$ & .05 \\
& & & & & & 1.00 & $.47^{* * *}$ & $.34 * *$ & .15 \\
& & & & & & & 1.00 & $.51 * * *$ & .13 \\
& & & & & & & & 1.00 & .12 \\
\end{tabular}

Mean differences in GES course completion for antecedents, GCI, and prosocial values. To examine possible demographic effects, we first bootstrapped $(n=5000)$ one-way ANOVAS for GES course completion, graduation status, study abroad experience, citizenship, and risk factors (whether the student was a person of color, first-generation college student, and/or a Pell grant recipient) for all variables under consideration. There were no significant differences for four of the independent variables: GES course completion, study abroad experience, citizenship, and risk factors (see Table 4). There was, however, a difference in means for graduation status for three variables: social justice, intergroup helping, and responsibility to act. For all three variables, the means for current students were higher than the means for graduated students (see Table 5).

Table 4. ANOVA Bootstrap $(n=5000)$ Examining for Differences Between GES and No GES Students

\begin{tabular}{|c|c|c|c|c|c|c|c|c|}
\hline & \multicolumn{3}{|c|}{ GES Course $(n=37)$} & \multicolumn{3}{|c|}{ No GES Course $(\mathrm{n}=28)$} & \multirow{3}{*}{$F$ test } & \multirow{3}{*}{$P$ value } \\
\hline & \multirow{2}{*}{ Mean (SE) } & \multicolumn{2}{|c|}{$95 \% \mathrm{CI}$} & \multirow{2}{*}{ Mean (SE) } & \multicolumn{2}{|c|}{$95 \% \mathrm{CI}$} & & \\
\hline & & $\underline{\text { Lower }}$ & Upper & & $\underline{\text { Lower }}$ & Upper & & \\
\hline Normative Environment & $4.78(.13)$ & 4.55 & $\overline{5.02}$ & $4.53(.18)$ & 4.14 & 4.91 & 1.33 & .25 \\
\hline Global Awareness & $5.04(.15)$ & 4.70 & 5.32 & $5.28(.12)$ & 5.04 & 5.50 & 1.45 & .23 \\
\hline Global Citizenship & $4.68(.16)$ & 4.34 & 5.00 & $4.46(.22)$ & 4.02 & 4.86 & .65 & .42 \\
\hline Intergroup Empathy & $5.18(.14)$ & 4.89 & 5.44 & $5.21(.16)$ & 4.87 & 5.53 & .03 & .86 \\
\hline Valuing Diversity & $5.43(.12)$ & 5.22 & 5.64 & $5.32(.10)$ & 4.94 & 5.64 & .32 & .57 \\
\hline Social Justice & $5.46(.09)$ & 5.29 & 5.63 & $5.41(.14)$ & 5.11 & 5.68 & .10 & .75 \\
\hline Environmental & $5.69(.08)$ & 5.51 & 5.83 & $5.48(.17)$ & 5.12 & 5.77 & 1.51 & .22 \\
\hline \multicolumn{9}{|l|}{ Sustainability } \\
\hline Intergroup Helping & $5.49(.10)$ & 5.27 & 5.69 & $5.32(.17)$ & 4.95 & 5.64 & .74 & .39 \\
\hline Responsibility to act & $5.51(.10)$ & 5.31 & 5.69 & $5.30(.16)$ & 4.945 & 5.61 & 1.41 & .24 \\
\hline
\end{tabular}

Note: $n=65.95 \%$ BCa CI = Bias Corrected accelerated (BCa) Bootstrapped Confidence Interval. There were no significant differences in this model.

Table 5. ANOVA Bootstrap ( $n=5000)$ Examining for Differences Between Current Students and Graduated Students

\begin{tabular}{|c|c|c|c|c|c|c|c|c|}
\hline & \multicolumn{6}{|c|}{ Current Student $(n=31)$} & \multirow{4}{*}{$F$ test } & \multirow{4}{*}{$P$ value } \\
\hline & & & & \multicolumn{3}{|c|}{ Graduated $(n=34)$} & & \\
\hline & \multirow[t]{2}{*}{ Mean (SE) } & \multicolumn{2}{|l|}{$95 \% \mathrm{CI}$} & Mean (SE) & $95 \% \mathrm{CI}$ & & & \\
\hline & & Lower & Upper & & Lower & Upper & & \\
\hline Normative Environment & $4.75(.15)$ & $\overline{4.48}$ & $\overline{5.01}$ & $4.61(.16)$ & $\overline{4.31}$ & $\overline{4.91}$ & .42 & .52 \\
\hline Global Awareness & $5.06(.17)$ & 4.65 & 5.37 & $5.22(.10)$ & 5.03 & 5.43 & .71 & .40 \\
\hline Global Citizenship & $4.79(.16)$ & 4.47 & 5.10 & $4.39(.19)$ & 3.98 & 4.76 & 2.35 & .13 \\
\hline Intergroup Empathy & $5.16(.15)$ & 4.85 & 5.40 & $5.22(.14)$ & 4.93 & 5.51 & .08 & .78 \\
\hline Valuing Diversity & $5.54(.11)$ & 5.29 & 5.79 & $5.24(.15)$ & 4.92 & 5.52 & 2.67 & .11 \\
\hline Social Justice & $5.61(.07)$ & 5.46 & 5.77 & $5.27(.12)$ & 5.01 & 5.51 & 5.17 & $.03 *$ \\
\hline Environmental Sustainability & $5.71(.09)$ & 5.50 & 5.89 & $5.50(.13)$ & 5.21 & 5.73 & 1.58 & .21 \\
\hline Intergroup Helping & $5.71(.08)$ & 5.54 & 5.88 & $5.15(.15)$ & 4.81 & 5.46 & 10.06 & $.00 *$ \\
\hline Responsibility to act & $5.66(.10)$ & 5.45 & 5.85 & $5.21(.10)$ & 4.92 & 5.47 & 7.37 & $.01 *$ \\
\hline
\end{tabular}

Note: $n=66.95 \% \mathrm{BCa} \mathrm{CI}=$ Bias Corrected accelerated (BCa) Bootstrapped Confidence Interval. * Indicates a statistically significant $p$ value $<.05$. 
In addition, because there were differences in means for graduation status among several variables, we bootstrapped $(n=5000)$ a 2 (GES course completion) by 2 (Graduation Status) MANOVA on all variables to examine for possible interaction effects. However, there were no significant differences for the interaction effect $\left[F(9,53)=.47\right.$; Wilk's $\lambda=.93, p=.89$; partial $\eta^{2}=$ .08]. In addition, we also bootstrapped $(n=5000)$ a 2 (GES, non-GES) MANOVA controlling for graduation status, but found no significant multivariate main effect $[F(9,54)=.52$; Wilk's $\lambda=.92, p$ $=.86 ;$ partial $\left.\eta^{2}=.08\right]$.

\section{Stage II: Path Model}

The proposed path model was based on Reysen and Katzarak-Miller's (2013a) model of global citizenship, where normative environment and global awareness predict global citizenship, and global citizenship predicts six prosocial outcomes (intergroup empathy, valuing diversity, social justice, environmental sustainability, intergroup helping, and responsibility to act). Before testing whether GES course completion moderated the model, we first examined the model without moderation. Although previous research (e.g., Blake et al., 2015; Reysen \& Katzarak-Miller, 2013a; Reysen et al., 2012) used individual items in a structural equation model, we included scale means, as smaller sample sizes in conjunction with many indicators affected our solution propriety (Gagné \& Hancock, 2006).

The model exhibited adequate fit ${ }^{1}, \mathrm{CFI}=.97$; TLI $=.90 ;$ RMSEA $=.08 ; 90 \%$ C.I. RMSEA $=$ $.00-.16 ;$ SRMR $=.05 . ; \chi^{2}(17, N=69)=17.05 ; p=.15$ (see Figure 1). As expected, normative environment was moderately and positively related to global citizenship; however, there was only a weak, non-statistically significant positive relation between global awareness and global citizenship. Global citizenship was moderately, positively, and significantly related to four of the prosocial values: intergroup empathy, valuing diversity, intergroup helping, and responsibility to act. Global citizenship was positively, but not significantly, related to the remaining two prosocial values: social justice and environmental sustainability.

Figure 1. Path Model for Hypothesized Model of Global Citizenship General Model.

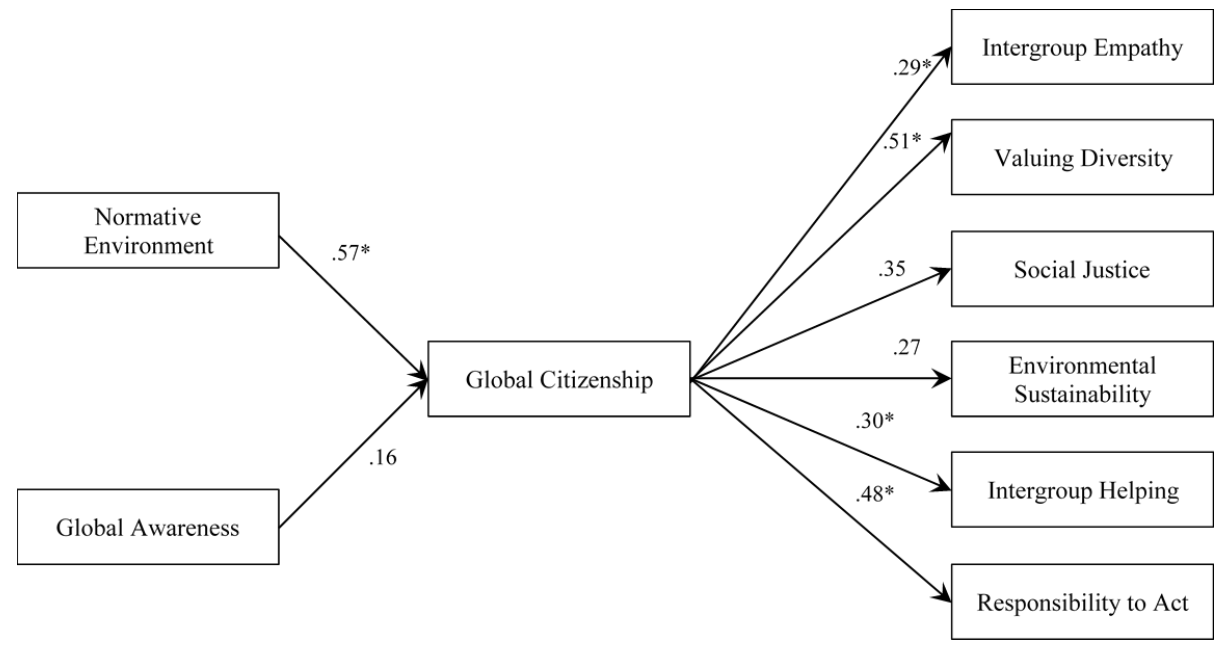

\footnotetext{
${ }^{1}$ We initially ran the model controlling for graduation status on all variables. However, as this variable made no
} significant difference in the model, we dropped it from further consideration. 
Note: $n=68$. All paths are standardized point estimates. Correlations between normative environment and global awareness, and among the prosocial values were estimated, but were not included in the model for ease of presentation. *Indicates that $95 \%$ Bias Corrected CI does not cross zero.

\section{Stage III: Moderated Path Model}

Finally, we employed multi-group structural equation modeling (MSEM) to examine GES course completion effects in the path model. Following Bollen \& Long (1993), we individually tested each pathway, examining for significant differences using a chi-square difference test. The final moderated model had adequate model fit, $\mathrm{CFI}=.96$; $\mathrm{TFL}=.90$; $\mathrm{RMSEA}=.08 ; 90 \% \mathrm{CI}$ RMSEA $=$ $.00-.16 ;$ SRMR $=.11 ; \chi^{2}(29, N=69)=35.60 ; p=.18$. There were three pathways moderated by GES course completion: (1) the path from global awareness to global citizenship; (2) the path from global citizenship to social justice; and (3) the path from global citizenship to environmental sustainability (see Figure 2 for the moderated path model).

\section{Figure 2. Path Model For Hypothesized Model of Global Citizenship Moderated by GES Course Completion}

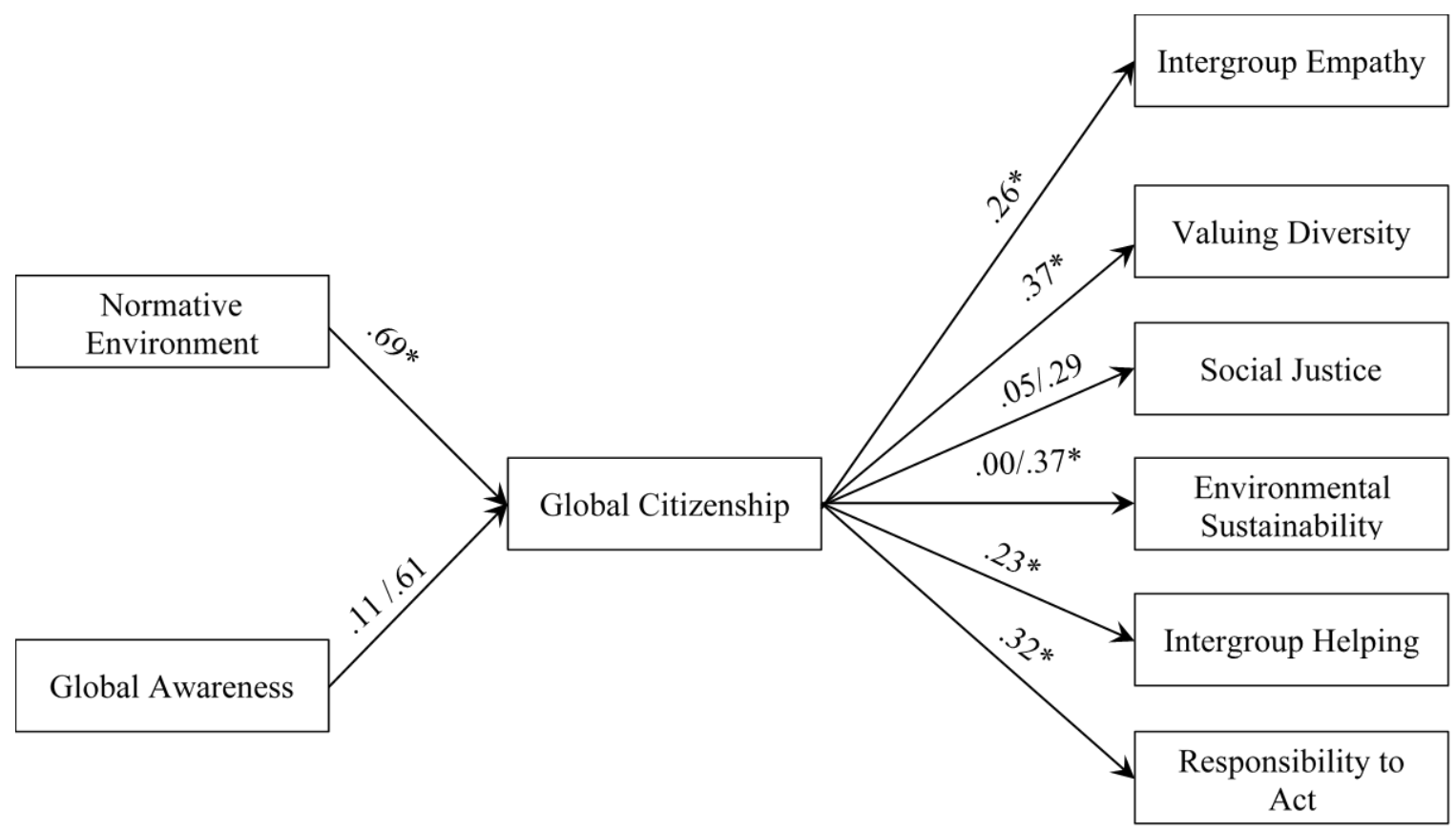

Note: $n=68$. For comparison purposes, all paths are unstandardized point estimates. For moderated path, GES course on the left/No GES on the right. Correlations between normative environment and global awareness, and among the prosocial values were estimated, but were not included in the model for ease of presentation.

* Indicates that $95 \%$ Bias Corrected CI does not cross zero.

For two of the moderated paths (global awareness $\rightarrow$ global citizenship and global citizenship $\rightarrow$ social justice), both pathways for GES course completion and non-course completion were not statistically significant; however, in both cases the effect sizes were positive and surprisingly stronger for students who had not participated in a GES course. For the remaining path (global citizenship $\rightarrow$ environmental sustainability), there was a statistically significant and positive relation, but only for 
students who had not completed a GES course. All other non-moderated paths in the model were significant, positive, and reflective of the initial path model.

\section{Discussion}

The purpose of the present study was to examine whether participation in the GES program would have stronger influences on students' global citizenship (antecedents, identification, and prosocial values), compared to a comparison group. The study findings did not support our hypothesis that GES program participation would have stronger influences on the model compared to non-GES program participation. In fact, in two of the three pathways moderated by GES completion-(1) the path from global citizenship to social justice and (2) the path from global citizenship to environmental sustainability-the effects were stronger for students who had not participated in a GES course. We were somewhat surprised by these results, as previous studies have shown strong differences in the means based on course participation when the course has global content (Blake et al., 2015; Reysen et al., 2012). The findings of the present study suggest that outcomes with regard to faculty-led programs do not have the same positive effects identified in previous literature. We offer three potential explanations for the inconsistencies: possible on-campus effects, possible study abroad impact, and possible limitations of GES programs as an enhancer.

We suggest that in cases where all students (as is the case with participants of the present study) may have a global worldview as a default identity, there is likely to be limited variation between the groups despite course completion. Students in the present study may have this identity by virtue of attending a college that defines itself as "global." Indeed, this expression pervades the language on the College's website and the descriptions of courses across many departments. The mission of the College is to develop its students into "engaged global citizens" and "leaders to address society's challenges." In the most recent academic year, undergraduate students (total under 3,000) came from 48 states and over 70 countries, with 32\% students of color and 18\% first-generation students. The college offers courses of study in 13 different languages, as well as several programs in interdisciplinary areas and international studies. Additionally, over the past five years, more than half of the students have studied abroad on six continents in sixty countries, with England, Spain, Switzerland, and France hosting the largest numbers of students during this period. Faculty members teach more than 400 courses relating to international issues and many more that examine different cultures within the United States. More than half of the college's graduates have taken at least one course with a significant focus on global/international issues and problems, and nearly $80 \%$ of graduates have taken a multicultural course addressing issues of race, ethnicity, gender, class, religion, or sexual orientation. The college's "global culture" (including on-campus courses, cocurricular offerings, and domestic service-learning/internship experiences that have global citizenry content) may be responsible for the lack of variety seen between GES participants and non-GES participants with regard to GCI and prosocial values. Salisbury et al. (2013), in their exploration of the limited effects of study abroad on intercultural competence, noted that pre-college characteristics, campus diverse interactions and integrative experiences can influence results. In the present study, it is possible that self-selection to a globally focused college or campus effects are strong enough to affect students' self-identification as global citizens, along with their endorsement of prosocial values, and that GES program participation does not make a substantial difference in this regard. 
It is also possible that GES program experience, on its own, may not have sufficient strength to significantly influence GES program participants' GCI and prosocial values beyond the default levels shared by all students, especially when study abroad is not accounted for. In this study, almost one quarter of the participants were international students, and thus had additional study abroad experience in addition to the GES course. In addition, almost 30\% of non-GES students had a long-term study abroad experience by the time they completed the survey. It is also possible that there are different effects from GES program participation, study abroad, or a combination of GES participation and study abroad, but because of our sample size we were not able to examine those differences.

Another possible explanation of limited differences between the two groups relates to GES program content. Study abroad literature indicates that not just any international experience can enhance global citizenship. In an experimental study of short-term study abroad and home campus course experiences, Tarrant et al. (2014) found that the level of influence of study abroad on global citizenship depended on a combination of two factors: the location and academic focus of the experience. Because the GES program comprised 12 different experiences (in terms of academic topics, location abroad, types of service learning, etc.), it is possible that not all of them had sufficiently combined explicit focus on global citizenry content with immersive service learning experiences to positively influence GCI and prosocial attitudes beyond college default levels. Indeed, our findings indicate that compared to participants who completed a GES course, non-GES course completion had positive and significant associations between GCI and environmental sustainability. Thus, it may not be the completion of any GES that influences global citizenry, but the type of GES that matters. Indeed, the focus of the GESs in this study ranged from geology in Europe to gender politics in Africa, and it is possible that this wide range of courses influenced students' perceptions regarding global citizenry differently. Future research should explore the kind of GES content that can increase global citizenship in students. As noted by others (e.g., Landon et al., 2017; Tarrant et al., 2014), such content would need to reflect a deliberate integration of academic and field components. Although the present study was not designed to assess the GES program, we suspect that a more deliberate infusion of themes associated with global citizenry in both the academic and service learning components may yield different results for GES participants. Due to a small sample size, we were not able to assess variation between the twelve GES courses in this regard.

\section{Limitations}

Although the present study highlighted the role that GES plays in influencing the antecedents and outcomes of GCI, there are limitations that should be considered when interpreting and generalizing the results. First, as noted above, it is important to acknowledge that because this study had a smaller sample size compared to similar studies in this area, we were not able to untangle or examine the additive effects of GES participation and study abroad on the model. Given that research has mixed findings about the impact of short-term study abroad experiences (Mulvaney, 2017; Salisbury et al., 2013; Tarrant et al., 2014), future research should examine the individual contribution that short-term GES programs and longer study abroad experiences have on students' global citizenship identification. Additionally, it is also possible that this study did not have adequate power to significantly identify all the effects of the GES program, and that could explain some of the non-significant findings. 
In addition, the participants were all female, and included currently enrolled undergraduate students and graduated students, as well as international and U.S. citizens. Since this study is the first that we have identified to include these unique populations, we do not know the extent to which their inclusion influenced these findings. For example, we found that graduated students reported significantly lower prosocial outcomes than currently enrolled undergraduate students; however, when we controlled for these demographics, we found no changes in the model. Future research should examine whether GES-like programs and their relationship to global citizenship attenuate over time, or whether the impact of these experiences is relatively stable.

Although common in the literature, this survey only addressed students' self-reported perceptions and beliefs about prosocial behaviors, and did not include items that identified behaviors, actions, or activities. This is potentially problematic, as the reliance on self-reporting raises the concern that participants may have given politically correct answers because of their affiliation with a college that expresses "being global" as a desired educational outcome. To counteract this, it would be helpful for future studies to gather information on activities associated with the different meanings of global citizenship. For example, civic engagement, advocacy, and membership in social transformation organizations are behaviors aligned with a critical view of global citizenship. "Academic tourism" (Di Gregorio, 2015), "voluntourism” (Baillie Smith \& Laurie, 2011) and philanthropy couched in noblesse oblige can reinforce neoliberal and Western centric notions of global citizenship (Mule, 2017). We note that although there are recent studies that have examined global citizenship behaviors in short-term study abroad (Drnach et al., 2016; Mulvaney, 2017; Murphy, Sahakyan, Yong-Yi, \& Magnan, 2014), the field would benefit from a robust conversation on ways that participant actions and behaviors align with different and often competing meanings of global citizenship.

In addition to not considering the impact the individual GES course had on the student, we did not employ a pre-/post-test experimental design to establish whether any differences between the GES group and the comparison group were due to pre-existing attitudes about global citizenship. Research in this area should also consider not only the specific GES course that was taken, but also whether, using a pre/post design, the course made a difference in students' global citizenry. Finally, it was not possible to establish causal relations in our model, as the present study is correlational.

\section{Conclusion}

Does participation in short-term, faculty-led global engagement programs, as defined in this paper, strongly influence participants' global citizenship when compared to that of non-participants? This is an important question for higher education institutions, in light of the increased emphasis on short-term study abroad programs. As Landon et al. (2017) noted, "the extent to which study abroad adds value beyond what is possible on campus needs to be demonstrated" (p. 1). The present study sought to understand the value added by comparing the perceptions of students who had completed a GES course to those who did not-in their self-identification as global citizens and in their endorsement of prosocial values. It appears from the findings of this study that the GES program (which consisted of 12 distinct interdisciplinary courses focused on different topics and themes, but with a complementary international travel and service-learning component) did not lead to significant differences in participants' self-identification as global citizens, compared with nonparticipating students. Nor did participants endorse prosocial values more than the comparison 
group. If the primary goal of the GES program is to enhance global citizenship, then it needs to be deliberate about course content and design.

Content in short-term study abroad matters (DeLoach, Kurt, \& Olitsky, 2015). To reach the goal of developing global citizenship beyond college default levels, faculty designing and leading short-term study abroad programs must intervene more intentionally to cultivate the values and actions that are aligned with the desired global citizenship. Themes and actions targeted at enhancing global citizenship would need to be identified ahead of time, communicated clearly to students, and infused into all the activities of the program; related learning outcomes would have to be assessed directly after, as well as long after, the program. Examples of themes often associated with the radical and critical meanings of global citizenship may include pro-environmentalism, social justice, human rights, intergroup empathy, and social responsibility. These can be incorporated irrespective of the field of study. Targeted actions and behaviors may include sustainable practices, development volunteerism (Devereux, 2008), and joining and being active in prosocial organizations, groups, and networks. In addition to content, students can be taught integrative and reflective thinking that leads to internalization of knowledge and a deeper understanding of self as global citizen. When assessment, preferably pre/post experimental design, shows a gap in attainment of program goals, then adjustments can be made resulting in continuous improvement.

Although the present study was not designed to assess all aspects of the GES program, we believe the adoption of a design approach may add value to the GES program with regard to developing global citizenship. We join others who have argued for using global citizenship as a theoretical construct around which to design and assess short-term, faculty-led programs (Coryell et al., 2016; Landon et al., 2017). As Landon et al. (2017) argued, program improvement and evaluation are enabled through robust, theory driven evidence-based research. Faculty-led global engagement programs present an opportunity to explore this theory-outcome nexus regarding global citizenship. The college from which the participants of the present study come has embraced design thinking and is working toward integrating this approach across the disciplines. We are excited to see what a design approach may contribute as faculty continue to engage their students in short-term study abroad. We believe, in the words of Landon and colleagues (2017), that "transforming students into global citizens requires pedagogy that is attentive to instructional design and rooted in theory" (p. 6). In general, short-term, faculty-led global engagement programs can benefit from such an approach.

Finally, this study revealed the need to address a few design concerns in future studies related to short-term, faculty-led study abroad programs. As noted in the limitations section, future studies can benefit from larger sample sizes, as well as diversity in samples. It would also be useful to include in such studies measures of pro-social behaviors associated with global citizenship, as opposed to solely perceptions or intentions. We anticipate that examining actions and activities related to global citizenship may not only provide a better indicator of global citizenship, it may also produce differences in results between the study abroad and non-study abroad groups. We point out that it would be useful to use a comparative group (as in the present study), to determine whether shortterm global experiences have added value regarding global citizenship. Further, we join others who have argued for examination of the long-term sustainability of global citizenry behaviors associated with study abroad (see DeGraaf, Slagter, Larsen, \& Ditta, 2013; Drnach et al., 2016; Mulvaney, 2017; Murphy et al., 2014; Paige, Fry, Stallman, Josic, \& Jon, 2009). In sum, a comparative, longitudinal and 
quasi-experimental study of global citizenry perceptions, behaviors and actions would allow for examination of the actual and sustained effects of short-term global engagement programs.

\section{References}

Aktas, F., Pitts, K., Richards, J. C., \& Silova, I. (2016). Institutionalizing global citizenship: A critical analysis of higher education programs and curricula. Journal of Studies in International Education, 21(1), 65-80. https://doi.org/10.1177/1028315316669815

Baillie Smith, M. \& Laurie, N. (2011). International volunteering and development: Global citizenship and neoliberal professionalisation today. Transactions of the Institute of British Geographers, 36(4), 545-559. https://doi.org/10.1111/j.1475-5661.2011.00436.x

Barkin, G. (2016). Undergraduate research on short-term, faculty-led study abroad. Council on Undergraduate Research Quarterly, 36(4), 26-32.

Barrett, P. (2007). Structural equation modelling: Adjudging model fit. Personality and Individual Differences, 42(5), 815-824. http://dx.doi.org/10.1016/j.paid.2006.09.018

Bentler, P. M. (1990). Fit indexes, Lagrange multipliers, constraint changes and incomplete data in structural models. Multivariate Behavioral Research, 25(2), 163-172. http://dx.doi.org/10.1207/s15327906mbr2502_3

Berndt, A. E. (1998, August). "Typical" model features and their effects on goodness-of-fit indices. Paper presented at the 106th Annual Convention of the American Psychological Association, San Francisco, CA.

Blake, M. E., Pierce, L., Gibson, S., Reysen, S., \& Katzarska-Miller, I. (2015). University environment and global citizenship identification. Journal of Educational and Developmental Psychology, 5, 97107. doi:10.5539/jedp.v5n1p97

Bollen, K. A., \& Long, J. S. (Eds.). (1993). Testing structural equation models. Newbury Park, CA: Sage.

Chieffo, L., \& Griffiths, L. (2004). Large-scale assessment of student attitudes after a short-term study abroad program. Frontiers: The Interdisciplinary Journal of Study Abroad, 10, 165-177.

Coryell, J. E., Stewart, T., Wubbena, Z. C., Valverde-Poenie, T. C., \& Spencer, B. J. (2016). International service-learning: Study abroad and global citizenship. In D. Velliaris (Ed.), Handbook of research on study abroad programs and outbound mobility (pp. 420-445). Hershey, PA: IGI Global.

DeGraaf, D., Slagter, C., Larsen, K., \& Ditta, E. (2013). The long-term personal and professional impacts of participating in a study abroad program. Frontiers: The Interdisciplinary Journal of Study Abroad, $23,42-59$.

DeLoach, S. B., Kurt, M., \& Olitsky, N. H. (2015). Does content matter? Analyzing the change in global awareness between business- and nonbusiness-focused short-term study abroad courses. Journal of Teaching in International Business, 26(1), 4-31. https://doi.org/10.1080/08975930.2014.929512

Devereux, P. (2008). International volunteering for development and sustainability: outdated paternalism or a radical response to globalisation? Development in Practice, 18(3), 357-370. doi: $10.1080 / 09614520802030409$

Di Gregorio, D. (2015). Fostering experiential learning in faculty-led study-abroad programmes. In V. Taras \& M. A. Gonzalez-Perez (Eds.), The Palgrave handbook of experiential learning in international business (pp. 569-584). London: Palgrave Macmillan.

Drnach, M. D., Ruby, C., Kluender, K., Palomba, B., \& Ursick, M. (2016). Assessing global citizenship after participation in service learning in physical therapy education. Journal of Community Engagement \& Higher Education, 8(2), 15-27.

Dwyer, M. M. (2004). More is better: The impact of study abroad program duration. Frontiers: The Interdisciplinary Journal of Study Abroad, 10, 151-163.

Fisher, C. M., \& Grettenberger, S. E. (2015). Community-based participatory study abroad: A proposed model for social work education. Journal of Social Work Education, 51(3), 566-582. https://doi.org/10.1080/10437797.2015.1046342 
Gagné P., \& Hancock, G.R. (2006). Measurement model quality, sample size, and solution propriety in confirmatory factor models. Multivariate Behavioral Research, 41, 65-83. https://doi.org/10.1207/s15327906mbr4101_5

Gibson, S. A., \& Reysen, S. (2013). Representations of global citizenship in a school environment. International Journal of Education Research, 8, 116-128.

Graham N., \& Crawford P. (2012). Instructor-led engagement and immersion programs: Transformative experiences of study abroad. Journal of Higher Education Outreach and Engagement, 16, 107-109.

Gullekson, N. L., Tucker, M. L., Coombs Jr, G., \& Wright, S. B. (2011). Examining intercultural growth for business students in short-term study abroad programs: Too good to be true? Journal of Teaching in International Business, 22(2), 91-106. https://doi.org/10.1080/08975930.2011.615672

Ho, D., Imai, K., King, G., \& Stuart, E. (2007). Matching as nonparametric preprocessing for reducing model dependence in parametric causal inference. Political Analysis, 15, 199-236. doi:10.1093/pan/mpl013

Hu, L.T., \& Bentler, P.M. (1999). Cutoff criteria for fit indices in covariance structure analysis: Sensitivity under parameterized model misspecification. Structural Equation Modeling, 6, 1-55. doi: $10.1080 / 10705519909540118$

Keese, J. R., \& O'Brien, J. (2011). Learn by going: Critical issues for faculty-led study-abroad programs. The California Geographer, 51, 3-24.

Kehl, K., \& Morris, J. (2008). Differences in global-mindedness between short-term and semester-ling study abroad participants at selected private universities. Frontiers: The Interdisciplinary Journal of Study Abroad, 15, 67-79.

Kiely, R. (2004). A chameleon with a complex: Searching for transformation in international servicelearning. Michigan Journal of Community Service Learning, 10(2), 5-20.

Kline, R.B. (2005). Principles and practice of structural equation modeling. New York: The Guilford Press.

Kurt, M. R., Olitsky, N. H., \& Geis, P. (2013). Assessing global awareness over short-term study abroad sequence: A factor analysis. Frontiers: The Interdisciplinary Journal of Study Abroad, 23, 22-41.

Landon, A. C., Tarrant, M. A., Rubin, D. L., \& Stoner, L. (2017). Beyond "Just do it": Fostering higherorder learning outcomes in short-term study abroad. AERA Open, 3(1), 1-7. doi: $10.1177 / 2332858416686046$

Lee, J. \& Green Q. (2016). Unique opportunities: Influence of study abroad on Black students. Frontiers: The Interdisciplinary Journal of study Abroad, 28, 61-77.

Lewis, T. L., \& Niesenbaum, R. A. (2005). Extending the stay: Using community-based research and service-learning to enhance short-term study abroad. Journal of Studies in International Education, 9(3), 251-264. https://doi.org/10.1177/1028315305277682

Marsh, H. W., Hau, K. T., \& Wen, Z. (2004). In search of golden rules: Comment on hypothesis-testing approaches to setting cutoff values for fit indexes and dangers in overgeneralizing $\mathrm{Hu}$ and Bentler's (1999) findings. Structural Equation $\quad$ Modeling, 11(3), 320-341. https://doi.org/10.1207/s15328007sem1103_2

McKeown, J. S. (2009). The first time effects: The impact of study abroad on college student intellectual development. Albany, NY: State University of New York Press.

Mule, L. (2017). Towards critical global education worker subjectivity: An exploration of narratives of American women engaged in education-related international volunteerism. International Journal of Development Education and Global Learning, 8(2), 53-72. https://doi.org/10.18546/IJDEGL.8.2.05

Mullens, J. B., \& Cuper, P. (2012). Fostering global citizenship through faculty led international programs. Charlotte, NC: Information Age Publishing.

Mulvaney, M. K. (2017). The long-term impact of study abroad on honors program alumni. Frontiers: The Interdisciplinary Journal of Study Abroad, 29(1), 46-67.

Murphy, D., Sahakyan, N., Yong-Yi, D., \& Magnan, S. S. (2014). The impact of study abroad on the global engagement of university graduates. Frontiers: The Interdisciplinary Journal of Study Abroad, $24,1-24$. 
Muthén, L. K., \& Muthén, B. O. (1998-2017). Mplus user's guide (7th ed.). Los Angeles, CA: Muthén \& Muthén.

Paige, R. M., Fry, G. W., Stallman, E. M., Josic, J., \& Jon, J. (2009). Study abroad for global engagement: The long-term impact of mobility experiences. Intercultural Education, 20, S29-S44. https://doi.org/10.1080/14675980903370847

Perry, L., Stoner, K. R., Stoner, L., Wadsworth, D., Page, R., \& Tarrant, M. A. (2013). The importance of global citizenship to higher education: The role of short-term study abroad. British Journal of Education, Society \& Behavioral Science, 3(2), 184-194. doi: 10.9734/BJESBS/2013/2910

Randolph, J., Falbe, K., Manuel, A., \& Balloun, J. (2014). A step-by-step guide to propensity score matching in R. Practical Assessment, Research \& Evaluation, 19(18), 1-6.

Reysen, S., \& Katzarska-Miller, I. (2013a). A model of global citizenship: Antecedents and outcomes. International Journal of Psychology, 48, 858-870. doi: 10.1080/00207594.2012.701749

Reysen, S., \& Katzarska-Miller, I. (2013b) Student pathways to global citizenship. In C. Boyle (Ed.), Student Learning: Improving Practice, pp. 121-137. Hauppauge, NY: Nova.

Reysen, S., Larey, L. W., \& Katzarska-Miller, I. (2012). College course curriculum and global citizenship. International Journal of Development Education and Global Learning, 4(3), 27-40. https://doi.org/10.18546/IJDEGL.04.3.03

Reysen, S., Pierce, L., Spencer, C., \& Katzarska-Miller, I. (2013). Exploring the content of global citizenship identity. The Journal of Multiculturalism in Education, 9, 1-31.

Sachau, D., Brasher, N., \& Fee, S. (2010). Three models for short-term study abroad. Journal of Management Education, 34(5), 645-670. https://doi.org/10.1177/1052562909340880

Salisbury, M. H., An, B. P., \& Pascarella, E. T. (2013). The effect of study abroad on intercultural competence among undergraduate college students. Journal of Student Affairs Research and Practice, 50(1), 1-20. https://doi.org/10.1515/jsarp-2013-0001

Steiger, J. H. (1990). Structural model evaluation and modification: An interval estimation approach. Multivariate Behavioral Research, 25, 173-180. https://doi.org/10.1207/s15327906mbr2502_4

Tarrant, M. A., Rubin, D., \& Stoner, L. (2014). The added value of study abroad: Fostering a global citizenry. Journal of Studies in International Education, 18(2), 141-161. https://doi.org/10.1177/1028315313497589

Tucker, L. R., \& Lewis, C. (1973). A reliability coefficient for maximum likelihood factor analysis. Psychometrika, 38(1), 1-10. https://doi.org/10.1007/BF02291170

Walters, C., Charles, J., \& Bingham, S. (2016). Impact of short-term study abroad experiences on transformative learning: A comparison of programs at 6 weeks. Journal of Transformative Education, 15(2), 103-121. https://doi.org/10.1177/1541344616670034

Wang, J., Peyvandi, A., \& Coffey, B. S. (2014). Does a study abroad class make a difference in student's global awareness? An empirical study. International Journal of Education Research, 9(1), 152-162.

Zamastil-Vondrova, K. (2005). Good faith or hard data? Justifying short-term programs. International Educator, 14(1), 44-49. 